ORIGINAL ARTICLE

\title{
Head injuries: a study evaluating the impact of the NICE head injury guidelines
}

\author{
Z Hassan, M Smith, S Littlewood, O Bouamra, D Hughes, C Biggin, K Amos, A D Mendelow, \\ F Lecky
}

Emerg Med J 2005;22:845-849. doi: 10.1136/emj.2004.021717

See end of article for authors' affiliations

......................

Correspondence to: Zia Hassan, Emergency Medicine, Hope Hospital Salford, 13 Minister Drive, Urmston, Manchester, M41 5HA; ziauddin_hassan@yahoo. com

Accepted for publication 22 March 2005

\begin{abstract}
Background: The NICE head injury guidelines recommend a different approach in the management of head injury patients. It suggests that CT head scan should replace skull $x$ ray (SXR) and observation/ admission as the first investigation. We wished to determine the impact of NICE on SXR, CT scan, and admission on all patients with head injury presenting to the ED setting and estimate the cost effectiveness of these guidelines, which has not been quantified to date.

Design: Study of head injury patients presenting to two EDs before and after implementation of NICE guidelines

Methods: The rate of SXR, CT scan, and admission were determined six months before and one month after NICE implementation in both centres. The before study also looked at predicted rates had NICE been applied. This enabled predicted and actual cost effectiveness to be determined.

Result: 1130 patients with head injury were studied in four 1 month periods (two in each centre). At the teaching hospital, the CT head scan rate more than doubled (3\% to $7 \%$ ), the SXR declined (37\% to $4 \%$ ), while the admission rate more than halved ( $9 \%$ to $4 \%$ ). This represented a saving of $£ 3381$ per 100 head injury patients: greater than predicted with no adverse events. At the District General Hospital, the CT head scan rate more than quadrupled ( $1.4 \%$ to $9 \%$ ), the SXR dropped (19 to $0.57 \%$ ), while the admission rate declined (7\% to $5 \%$ ). This represented a saving of $£ 290$ per 100 head injury patients: less than predicted. Conclusion: The implementation of the NICE guidelines led to a two to fivefold increase in the CT head scan rate depending on the cases and baseline departmental practice. However, the reduction in SXR and admission appears to more than offset these costs without compromising patient outcomes.
\end{abstract}

$\mathrm{H}$ ead injuries are among the commonest type of trauma seen in emergency departments (ED), constituting 10$20 \%$ of all ED cases or one million patients per annum in the UK. ${ }^{12}$ The majority of these cases have minor or mild head injury. ${ }^{3}$ Under current practice, $74 \%$ have skull $x$ rays (SXR) even though it may reveal a fracture in only $2 \%$ of cases. ${ }^{45}$ Furthermore, each year there are 110000 admissions to hospitals in England, ${ }^{1}$ with a primary diagnosis of head injury but only 2000 patients require neurosurgery, the others being discharged after a period of observation. ${ }^{6}$

The National Institute for Health and Clinical Excellence (NICE) head injury guidelines issued in June 2003 recommend a different approach in the management of these patients. A guideline development group (GDG) looked at the evidence available on the best way of managing head injured patients and made recommendations for triage and early management based on this. ${ }^{7}$ There are differences from current established practice in the United Kingdom ${ }^{8}$ and from the recent guidelines issued by the Royal College of Surgeons of England and the Scottish Intercollegiate Guidelines Network (SIGN). ${ }^{9} 10$

The major change suggests that computed tomography (CT) head scan replaces SXR and observation/admission as the first investigation.

The recommendations and indication for skull $x$ ray and CT scan are summarised in boxes 1 and 2

The GDG envisaged these recommendations would improve care. They recognised there would be a significant increase in the number of CT head scans requested by United Kingdom EDs but this would be counterbalanced by a reduction in SXRs and admissions. No estimate of cost effectiveness was made on practice based data. Concern has been expressed about this in reactions to the issue of the guidelines. ${ }^{11-17}$

Recent work in the United Kingdom has shown that the application of the Canadian CT head rules ${ }^{18}$ (on which the NICE head injury guidelines for CT are based) in adult patients with minor head injury (presenting with GCS 13-15; GCS 15 patients having some loss of consciousness/amnesia) increased the rate of CT scans from 14 to $20 \%$ of patients. ${ }^{14}{ }^{15}$ In children, a recent report estimated that rate would increase up to $6-9 \%{ }^{8}$ However, no paper to date has studied the impact of the NICE guidelines on the population to which they apply-all patients with head injury presenting to EDs regardless of age or severity. We wished to determine the predicted and actual cost effectiveness of these guidelines applied to all head injured patients in two United Kingdom centres.

\section{METHOD}

The study centres were the EDs of an inner city teaching hospital with on-site Regional Neurosciences (Hope Hospital, Salford) and a District General Hospital (North Tyneside General Hospital (NTGH)).

Box 1 Skull $x$ ray recommendations: NICE guidelines

- Suspicion of non-accidental injury in infant and young children.

- Where CT scanning resources are unavailable. 


\section{Box 2 Cranial CT scanning: NICE guidelines}

Are any of the following present?

- Glasgow Coma Score (GCS) <13 at any point since the injury.

- GCS 13 or 14 at two hours after the injury.

- Focal neurological deficit.

- Suspected open or depressed skull fracture.

- Any sign of basal skull fracture (haemotympanum "panda" eyes, cerebrospinal fluid otorrhoea, Battle's sign).

- Post traumatic seizure.

- $>1$ vomiting episode (clinical judgement on cause of vomiting and need for imaging should be used in children $\leqslant 12$ years)

The study was an analysis of anonymised data extracted from the patient record. During the study periods, all patients presenting with recent head injury were eligible for entry. Head injury was defined as any injury around the head and upper part of face and correlated with the discharge diagnosis (head injury). To ensure the capture of all patients with head injury, a manual search of the ED cards was made and the injuries correlated with the cause or mechanism of injury, including road traffic accident, assault, sport, falls, and nonaccidental injury. Data extracted included demography, variables relating to indications for imaging and admission, the imaging actually performed, and patient disposal.

There were two study periods: month A, six months before the implementation of NICE (November 2002 at NTGH and May 2003 at Hope), and month B, one month after the implementation of NICE (May 2003 at NTGH and January 2004 at Hope). Early implementation of NICE guidelines was possible at NTGH because of author membership of GDG; this was done by an intensive ED education and promotion exercise. At Hope, review of the month A results led to a modification of NICE CT guideline for GCS 15 patients between $10 \mathrm{pm}$ and $8 \mathrm{am}$ (in order to prevent out of hours scans on stable patients disrupting radiographer availability for working day neuroradiology lists). This was disseminated as an ED protocol in November 03 (fig 1).

The study outcome measures were the actual $(95 \%$ confidence interval (CI)) rates of admission, CT head scan, and SXR during month $\mathrm{A}$ and month $\mathrm{B}$ and the associated costs. Predicted rates (had NICE been applied) were also calculated for month A.

A secondary outcome measure was rate of any adverse event associated with practice in either month, such as representation because of missed injury. This (alongside local costing for imaging and admission) enabled the cost effectiveness of changing to NICE from current practice to be determined. Data were analysed using the Statistical Package for Social Sciences (version 11 SPSS). When comparing time periods, lack of overlap of $95 \%$ CI for the outcome measures was deemed to indicate a significant difference.

\begin{abstract}
Abbreviations: $C T$, computed tomography; $E D$, emergency department; GCS, Glasgow Coma Score; GDG, guideline development group; NICE, National Institute for Health and Clinical Excellence; NTGH, North Tyneside General Hospital; SIGN, Scottish Intercollegiate Guidelines Network; SXR, skull $x$ ray
\end{abstract}

ED, emergency department; GCS, Glasgow Coma Score; NTGH, North Tyneside General Hospital.

\section{RESULTS}

During each study period between $5 \%$ and $7 \%$ of the ED attendances had a head injury, the majority of patients being male and young. During any month studied, at least $96 \%$ of patients were GCS 15 on presentation. The intracranial abnormality rate on CT or post mortem was between $0.02 \%$ and $1.8 \%$ in the months sampled. Mortality was rare with a study range of $0-0.7 \%$. See table 1 .

\section{HOPE RESULTS}

Altogether, 221 head injured patients attended the ED of Hope Hospital, Salford, during the initial study period May 2003 (month A). Two hundred (90.5\%) were discharged home from the ED and 21 (9.5\%) were admitted.

Under the NICE head injury guidelines, only four patients out of the 21 would have required admission. A review of cases found that five more patients would not have been suitable for discharge because of alcohol intoxication or other social circumstances but nevertheless 12 patients could have been discharged without admission if it had been known that they had a normal CT head scan. This would have resulted in a saving of an extra three bed days per week or 12 bed days over the four weeks study period. If the current costing of a bed day in the trust of $£ 334$ was used, the additional savings from these admissions would be $£ 1670(334 \times 5)$ per 100 head injury patients.

SXR was performed in $81(36.8 \%)$ of cases seen in this period, of which 17 (21\%) were admitted and 64 (79\%) discharged from the ED. CT scan was done in seven (3.2\%) head injured patients out of which five (71.8\%) were admitted and two $(28.6 \%)$ were discharged.

If the NICE head injury guidelines had been applied, no patients would have required SXR, 40 patients would have required CT scan, and 181 patients would have required no imaging.

Using these figures, and given local costing, the following changes every 100 head injury patients can be calculated. Not doing SXR would result in a saving of nearly $£ 2479$ ( $£ 67 \times$ 37), which should be added to the monthly saving from admission of $£ 1670$. On the other hand, 15\% more CT scans would have been required. The additional cost of these would be $£ 1875(£ 125 \times 15)$. Therefore the hypothetical application of the NICE head injury guidelines to this inner city teaching hospital ED could save approximately £2274 per 100 head injury patients.

During the second study period (January 2004) there were 282 head injury patients. Only four patients had GCS $<15$. Of these 282 head injury patients, 260 were discharged home, including 12 patients with normal CT scans. Of the remaining 22 patients admitted, eight more patients had CT scans prior to admission as inpatients. Of these eight patients, three were referred to the neurosurgeon, two were transferred to the Royal Manchester Children's Hospital, and three were admitted under the care of the ED because of social reasons or alcohol intoxication. A review of cases found that three more patients would not have been suitable for discharge because of alcohol intoxication or other social circumstances. Eleven patients were admitted under Medicine and Care of the elderly wards for reasons unrelated to head injury (medical cause of collapse/fall). Under the local modification, 11 patients had SXR because of low suspicion of depressed or open fracture but no other indication of CT scan.

If these rates of admission, SXR, and CT had been applied to the month A data the saving would have been $£ 3381.00$ per 100 head injury patients. See table 2 .

\section{North Tyneside results}

Altogether, 276 head injured patients attended NTGH during the first study period of November 2002. Two hundred and 


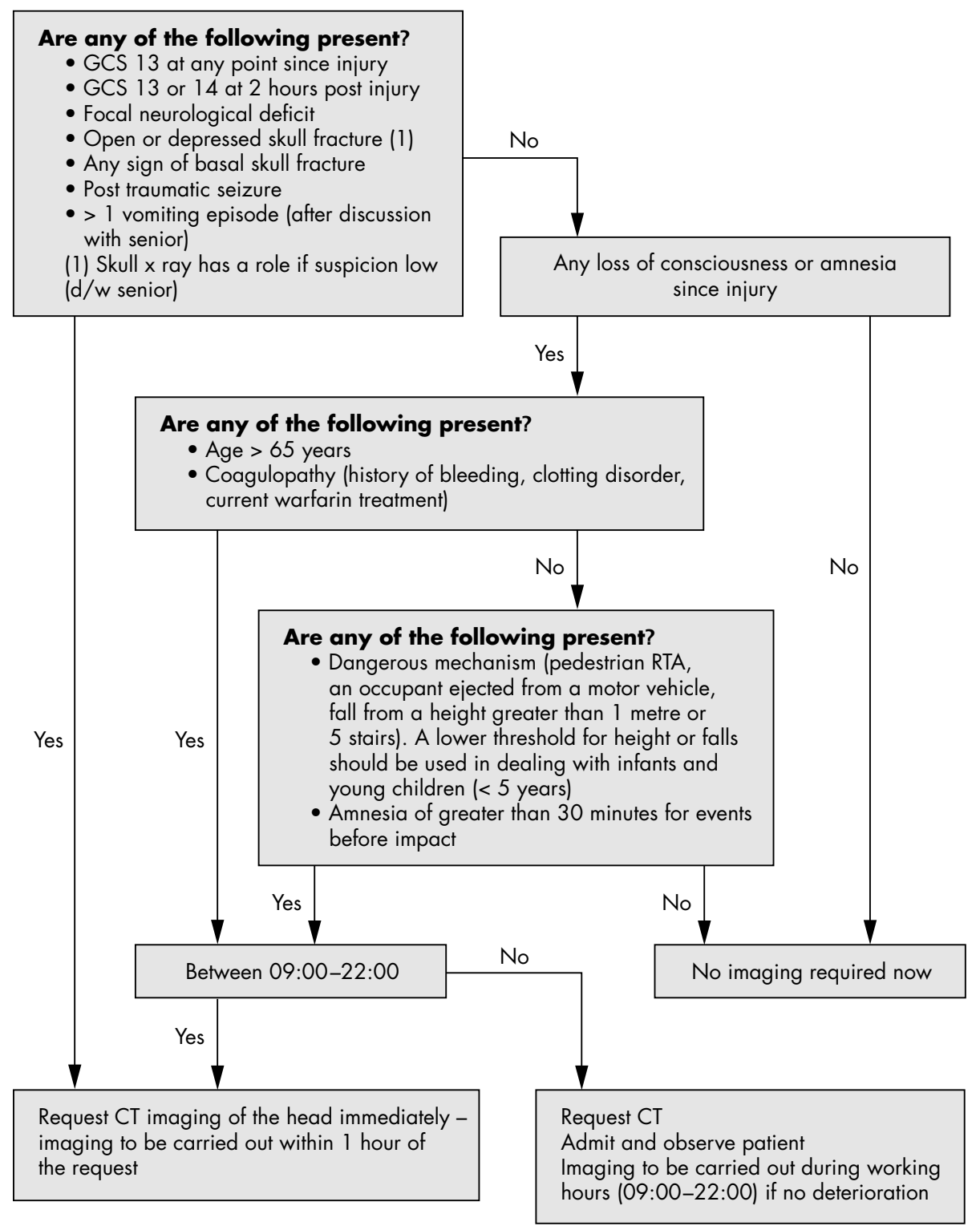

Figure 1 Hope Emergency Department head injury CT guidelines

fifty eight (93\%) were discharged home from the ED and 18 $(7 \%)$ were admitted. Under the NICE head injury guidelines, only eight patients out of 18 would have required admission and 10 patients could have been discharged without

Table 1 Baseline characteristics of patients in each centre by study period

\begin{tabular}{|c|c|c|c|c|}
\hline & Hope & NTGH & Hope & NTGH \\
\hline & Month A & Month A & Month B & Month B \\
\hline ED attendance (n) & 4761 & 4401 & 5586 & 5127 \\
\hline $\begin{array}{l}\% \text { (n) With head } \\
\text { injury }\end{array}$ & $5(221)$ & $6(276)$ & $5(282)$ & $7(351)$ \\
\hline$\%$ (n) Male & $68(150)$ & $66(181)$ & $64(181)$ & 63 (223) \\
\hline Median age & 20 & 20 & 23 & 25 \\
\hline$\%$ (n) Age < 16 & $42(94)$ & $42(116)$ & $36(103)$ & 35 (125) \\
\hline$\%$ (n) GCS $<15$ & $3.2(7)$ & $2.5(7)$ & $1.4(4)$ & $2.5(9)$ \\
\hline $\begin{array}{l}\% \text { (n) Intracranial } \\
\text { abnormality }\end{array}$ & $1.8(4)$ & $0.7(2)$ & $0.7(2)$ & 0.02 (1) \\
\hline \% (n) Mortality & $0.5(1)$ & $0.7(2)$ & $0(0)$ & $0.02(1)$ \\
\hline
\end{tabular}

admission if it had been known that they had a normal CT head scan. A review of cases found that two patients who died soon after presentations were included in this admission data and therefore in reality six patients would have required admission. Of these six patients, two were referred to neurosurgeons and transferred to Newcastle General Hospital and four patients were admitted under the care of ED because of social reasons or alcohol intoxication. If the current costing of a bed day in the trust was $£ 200$, the monthly additional cost of these admissions would be $£ 800$ $(£ 200 \times 4)$ per 100 head injury patients, which could potentially be saved.

SXR was performed in $52(19 \%)$ of cases seen in this period and CT scan was done in four (1.4\%) head injured patients. If the NICE head injury guidelines had been applied, no patients would have required SXR, 12 more patients would have required CT scan, and 260 patients would have required no imaging.

Not doing SXR would result in a saving of nearly £741 (39 $\times 19$ ), which should be added to the saving from admission of $£ 800$ per 100 head injury patients. On the other hand, $4.6 \%$ 


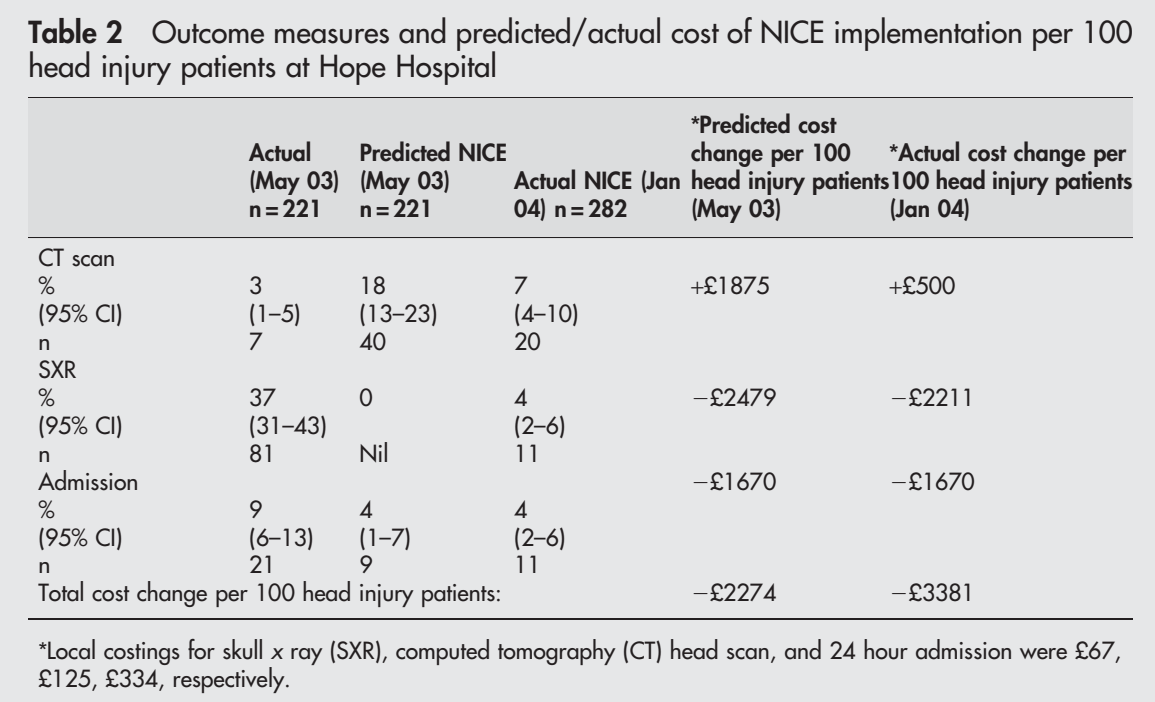

more CT scans would have been required. The additional cost of these would be $£ 501(£ 109 \times 4.6)$. Therefore, the hypothetical application of the NICE head injury guidelines to this district general hospital ED could potentially save $£ 1040$ per 100 head injury patients.

During the second study period (May 2003) at NTGH, a total of 5127 new patients were seen-351 were head injury patients. Of these, only nine patients had GCS $<15$ and 33 (9\%) patients had CT scans. Altogether, 324 (92.4\%) of the head injury patients were discharged home, including 15 with normal CT scan. Twenty seven patients were admitted. Nine patients were admitted under medicine and care of the elderly wards for investigation of the primary collapse or fall where minor head injury was an incidental finding. Eighteen (5\%) patients were admitted with head injury as a primary diagnosis-three patients were referred to neurosurgery, one died in the intensive care unit, and 14 patients were admitted because of social reasons or alcohol intoxication with normal CT findings. Under the new recommendation, two patients had SXR for investigation of suspected NAI but who had no other indication for CT.

If these month $\mathrm{B}$ rates of admission CT and SXR were applied to the NTGH Month A rates the cost saving falls to $£ 290$ per 100 head injury patients.
During the study there were no adverse events associated with clinical practice relating to imaging and admission. See table 3.

\section{DISCUSSION}

This two setting before and after study indicates that teaching and general hospital implementation of NICE head injury guidelines results in a highly significant reduction in SXR rate, a significant increase in CT rate, and a reduction in admission rates after head injury (in relation to the total head injury population attending EDs; however, there was, some variability in the results. The CT rate increased by a factor of 2.33 at Hope from 7 to 20. The predicted rate of increase was sixfold. This discrepancy is probably because of a reduction in the proportion of patients who presented with GCS $<15 ; 3.2 \%$ month A to $1.4 \%$ month B. It is also likely that the modified protocol implemented at Hope (which meant that GCS 15 head injury patients are not scanned after $10 \mathrm{pm}$ ) resulted in three additional admissions who could have been discharged with normal CT scans. This still, however, would not have pushed the CT rate up to $18 \%$. The remaining discrepancy (on looking at the data closely) appears to be because of a greater proportion of patients in month A presenting with "amnesia before injury $>30$

Table 3 Outcome measures and predicted/actual cost of NICE implementation per 100 head injury patients at North Tyneside General Hospital

\begin{tabular}{|c|c|c|c|c|c|}
\hline & $\begin{array}{l}\text { Actual } \\
\text { (Nov 02) } \\
n=276\end{array}$ & $\begin{array}{l}\text { Predicted NICE } \\
\text { (Nov 02) } \\
n=276\end{array}$ & $\begin{array}{l}\text { Actual NICE } \\
\text { (May 03) } \\
n=351\end{array}$ & $\begin{array}{l}\text { Predicted cost } \\
\text { change per } 100 \\
\text { head injury patients } \\
\text { (Nov 02) }\end{array}$ & $\begin{array}{l}\text { Actual cost change } \\
\text { per } 100 \text { head injury } \\
\text { patients (May 03) }\end{array}$ \\
\hline \multicolumn{6}{|l|}{ CT scan } \\
\hline $\begin{array}{l}\% \\
(95 \% \mathrm{Cl})\end{array}$ & $\begin{array}{l}1.4 \\
(0-3)\end{array}$ & 6 & 9 & $+£ 501$ & $+£ 828$ \\
\hline \multicolumn{5}{|l|}{ SXR } & \\
\hline $\begin{array}{l}\% \\
(95 \% \mathrm{Cl})\end{array}$ & $\begin{array}{l}19 \\
(14-22)\end{array}$ & 0 & $\begin{array}{l}0.57 \\
(0-1)\end{array}$ & -741 & $-£ 718$ \\
\hline Admission & 52 & \multicolumn{4}{|c|}{ Admission } \\
\hline $\begin{array}{l}\% \\
(95 \% \mathrm{Cl}) \\
\mathrm{n}\end{array}$ & $\begin{array}{l}7 \\
(4-10) \\
18\end{array}$ & $\begin{array}{l}3 \\
(1-5) \\
8\end{array}$ & $\begin{array}{l}5 \\
(2-6) \\
18\end{array}$ & $-£ 800$ & $-£ 400$ \\
\hline \multicolumn{4}{|c|}{ Total cost change per 100 head injury patients: } & $-£ 1040$ & $-£ 290$ \\
\hline
\end{tabular}


minutes" as an indication for CT. At NTGH the predicted CT rate increase from 1.4 to $6 \%$, a factor of 3.5 , is less than the actual increase to $9 \%$, which is a factor of 5.6. This has occurred despite similar proportions of patients with a low GCS. The discrepancy with the patients between month A and month $\mathrm{B}$ is because of an increased rate of patients who presented with vomiting more than once in month B.

Although the SXR rate reduced dramatically at both centres, the degree of change was much greater at North Tyneside than at Hope $(19 \% 0.57 \% \quad v \quad 37 \% 4 \%)$. This is explained by the modification to the guidelines at Hope suggesting SXRs for those patients with low suspicion of depressed or open skull fracture but who have no other indication for CT. All these SXRs were negative thus questioning the validity of this approach.

Both centres experienced a reduction in admission rates that was not statistically significant. The reduction at Hope was as predicted; at NTGH it was less than predicted because of an increase in the proportion of patients requiring admission for social reasons. It may be seen as anomalous that in both the centres "month B" periods there were 11 patients in either centre who required admission for medical rather than head injury reasons, whereas no presentations required this management during either of the month $\mathrm{A}$ samples.

The major weakness of the paper is that this was a case note analysis based study with cross checking of records of admissions of head injured patients and radiology records of imaging. We also checked for intensive care unit head injury admission during the period. This kind of study does not constitute the same level of evidence as a prospective study. We are confident, however, from our cross checking that we have not missed any head injured patients with significant intracranial abnormalities; it is conceivable we may have missed one or two patients with insignificant head injuries who attended the ED but were not admitted. This would be unlikely to significantly change the study results.

At first sight, however, our results may appear inconsistent with those of other studies, particularly those recently published from Cambridge. ${ }^{14}{ }^{15}$ The Cambridge study was an application of the Canadian CT head rules rather than NICE per se to adults with mild head injury. This appears to be about $25 \%$ of the sample that we studied. Although their before and after study did show a marked drop in SXR, their "before" CT rate was already high at $14 \%$ and increased to $20 \%$ (factor increase of 1.4). This is not the magnitude of increase that occurred in either of our settings, where the CT rate more than doubled at Hope and increased by more than a factor of 4 at North Tyneside. Logically the magnitude of increase in the rate of CT (most of which show no abnormality) facilitates greater discharge rates from the ED. Therefore it is not surprising we showed reductions in admission where no significant change in the Cambridge admission rate occurred. Our results are also consistent with some hypothetical work done in children, which suggested an increase in CT rate from 0.9 to $8.7 \%$ and a reduction in admission from 3.7 to $1.4 \%{ }^{8}$

Our interpretation of this data is that implementing NICE head injury guidelines in UK EDs will lead to significant reductions in SXR, significant increases in CT rate (although not alarming and still affecting less than $10 \%$ of patients), and are likely to result in reductions overall in the admission rate.

From our data, we think it is likely that these changes will be cost effective though the degree of cost effectiveness will depend to an extent on the baseline practices of the specific ED. However, in most settings we would conclude that the reductions in SXR and admission rate are more than likely to compensate in costs for the increase in CT rate. From these data, this change in practice also appears to be safe although both modes of practice appear to be safe in not missing injuries; however, a much bigger sample would need to be studied to be sure that this was the case in the month A and $\mathrm{B}$ periods. It is clearly a desirable end point that far lower numbers of patients were irradiated under NICE. The information contained in this paper may be of some reassurance to radiology departments in that for an average of one extra CT per day they will lose the workload of reporting large numbers of SXR, which are of little diagnostic utility.

\section{CONCLUSION}

We therefore conclude that cost effectiveness should not be a barrier for the implementation of the NICE head injury guidelines in UK EDs.

\section{ACKNOWLEDGEMENTS}

This study was sponsored and funded by Trauma audit and research network (TARN). The authors would like to thank all the TARN Staff, Emergency Medicine Departments, Hope Hospital, Salford, and North Tyneside General Hospital for their help, support, and contributions.

\section{Authors' affiliations}

Z Hassan, M Smith, S Littlewood, O Bouamra, D Hughes, F Lecky, Hope Hospital, Salford

C Biggin, K Amos, North Tyneside General Hospital, North Tyneside A D Mendelow, Neurosurgery Department, Newcastle General Hospital, Newcastle

Funding: this study was sponsored and funded by the Trauma audit and research network (TARN)

Competing interests: none declared

\section{REFERENCES}

1 Kay A, Teasdale G. Head injury in the United Kingdom. Word J Surg 2001;25:1210-20.

2 McMillan R, Greenwood R. Rehabilitation Programmes for the Brain Injured Adult: Current Practice and Future Opinions in UK. A discussion Paper for the department of Health. London: DoH, 1991 May).

3 Swann IJ, Teasdale GM. Current concepts in the management of patients with so-called 'minor' or 'mild' head injury. Trauma 1999;1:143-5.

4 De Lacey G, McCabe M, Constant O, et al. Testing a policy for skull radiography (and admission) following mild head injury. Br J Radiol 1990;63:14-8.

5 Gorman DF. The utility of post-traumatic skull X-Rays. Arch Emerg Med 1987:4:141-8.

6 Hospital Episode Statistics. 2000/2001. Department of health

7 National Institute for Clinical Excellence. Head injury in infants, children and adult: triage, assessment, investigation and early management. National Collaborative Centre for Acute Care. http://www.nice.org.uk (accessed 4 October 05).

8 Dunning J, Daly JP, Malhotra R, for the Emergency Medicine Research Group (EmeRGe), et al. The implication of NICE guidelines on the management of children presenting with head injury. Arch Dis Child. 2004;89: 763-7 10, 1136/adc.2003.042423., (8).

9 The Royal College of Surgeons. Report of the working Party on the Management of Patients with head injury. London, 1999.

10 The College Scotish Intercollegiate Guidelines Network. Early management of patients with head injury. SIGN, 2000

11 Swann IJ, Kelliher T, Kerr J. Are we ready for NICE head injury guidelines in Scotland? Emerg Med J 2004;21:401-2.

12 Shravat BP, Hynes KA. The impact of NICE guidelines for the management of head injury on the workload of the radiology department. Emerg Med $J$ 2004;21:521-2.

13 Leaman AM. The NICE guidelines for the management of head injury: the view from a district hospital. Emerg Med J 2004;21:400.

14 Sultan HY, Boyle A, Pereira M, et al. Application of the Canadian CT head rules in managing minor head injuries in a UK Emergency Department implication for the implementation of the NICE guidelines. Emerg Med J 2004;21:420-5.

15 Boyle A, Santarius L, Maimaris C. An evaluation of the impact of the Canadian CT head rule on British practice. Emerg Med J 2004;21:426-8.

16 T J Coats. NICE head injury guidelines. Emerg Med J 2004;21(4):402.

17 Lee JB. NICE head injury guidelines: cost implication for a district general hospital ("six scans to six figures"). Emerg Med J 2004;21:125-6.

18 Stiell IG, Wells GA, Vandemheen K, et al. The Canadian CT head rule for patients with minor head injury. Lancet 2001;357:1391-6. 